\title{
Scarf osteotomy in the management of symptomatic adolescent hallux valgus
}

\author{
N. G. Farrar • N. Duncan • N. Ahmed • \\ R. A. Rajan
}

Received: 13 November 2011 / Accepted: 6 March 2012/Published online: 17 March 2012

(C) EPOS 2012

\begin{abstract}
Purpose This study was designed to assess the utility of the scarf osteotomy in the management of symptomatic adolescent hallux valgus.

Materials and methods This is a case series of 29 patients (39 feet) with a mean follow up of 38.6 months (range 6-60 months). The mean age at the time of surgery was 14.1 years (range 10-17 years). American Orthopaedic Foot and Ankle Society (AOFAS) scores were collected at final follow up, along with a rating of the overall satisfaction. Any complications were recorded. Pre- and postsurgical radiographic angles were measured and analysed using the Student's $t$-test. The angles measured were the hallux valgus angle (HVA), the inter-metatarsal angle (IMA) and the distal metatarsal articular angle (DMAA). A second surgeon independently reviewed the angles in order to assess the inter-rater reliability using the Pearson product moment correlation.

Results The mean AOFAS score at final follow up was 94.2 (range 54-100). Of all patients, $93 \%$ were either satisfied or very satisfied with their final outcome. One patient has been listed for revision surgery after symptomatic recurrence at 3 years follow up. The pre-operative HVA, IMA and DMAA were $34.8^{\circ}, 15.9^{\circ}$ and $16.0^{\circ}$, respectively. The post-operative values were $16.3^{\circ}, 8.8^{\circ}$ and $9.2^{\circ}$, respectively $(p<0.001$ for each). Pearson's $r$ coefficient values demonstrated good inter-rater reliability of measurement.

Conclusion We have presented the results of the largest case series of scarf osteotomies for adolescent hallux
\end{abstract}

N. G. Farrar $(\bowtie) \cdot$ N. Duncan · N. Ahmed · R. A. Rajan

Department of Orthopaedics, Royal Derby Hospital,

Uttoxeter Road, Derby DE22 3NE, UK

e-mail: ngfarrar@doctors.org.uk valgus reported in the literature up to now, as far as we are aware. AOFAS scores at final follow up are comparable to the smaller studies previously reported and provide evidence that good outcomes and high levels of patient satisfaction can be achieved. Early follow up demonstrates a low level of symptomatic recurrence, but longer term data are still required.

Keywords Adolescent $\cdot$ Hallux $\cdot$ Valgus $\cdot$ Scarf . Osteotomy $\cdot$ Bunions

\section{Introduction}

The Z osteotomy was first described in 1926 [1]. In concept, it provided a very stable osteotomy, but as a technically demanding procedure, it could only be performed reproducibly after the introduction of the micro oscillating saw. The technique, therefore, emerged again in the 1970s and was later popularised by Barouk in Europe and Weil and Borelli in the USA [2, 3]. Scarf is now the popular term for the $\mathrm{Z}$ osteotomy and refers to a traditional carpentry technique. The splayed scarf joint was used by English joiners in the 12th to 14th centuries, before being superseded by other techniques [4].

Symptomatic adolescent hallux valgus represents a significant challenge for the orthopaedic surgeon. Conservative management fails to halt the progression of the deformity and the results have demonstrated high recurrence rates with both distal and double osteotomies [5-8]. It has been suggested that the scarf osteotomy has a good basis in treating adolescent hallux valgus because of its ability to allow rotational correction in addition to translation [9]. This can allow correction of the often very large distal metatarsal articular angle (DMAA), maintaining joint 
congruence after the hallux valgus angle (HVA) is reduced by the procedure. As far as we are aware, there have been three papers on the use of the scarf osteotomy in adolescent hallux valgus, reporting mixed results [9-11].

\section{Materials and methods}

Forty scarf osteotomies were performed for adolescent hallux valgus between 2006 and 2010. Of these, there were 29 girls (39 feet) and one boy. The boy had a hemiplegic cerebral palsy on the affected side and was, therefore, excluded from the study. Of the remaining 29 girls, 28 were available for clinical follow up in 2011, with one patient being untraceable in 2011 but who had been reviewed in 2010, had available radiographs and an American Orthopaedic Foot and Ankle Society (AOFAS) score, and, therefore, was included in the study. This left a case series of 29 patients ( 39 feet). Ten of these patients (12 feet) also underwent an Akin osteotomy.

Surgery was only offered after a careful consent process. Indications included pain that was interfering with schooling or social activities, progressive deformity that was making the fitting of sensible shoes difficult and failure of a reasonable attempt at conservative management.

All operations were either performed or directly supervised by the senior author. The technique employed was a single incision technique from the medial side. Careful sharp dissection exposes the metatarsophalangeal joint and the first metatarsal. On the plantar side of the metatarsal, periosteal stripping is minimised, with only enough exposure to allow the accurate placement of the bony cuts. A ' $\mathrm{Z}$ ' osteotomy is then performed, avoiding the basal first metatarsal physis, before the distal fragment is translated laterally. With a congruent joint, careful adjustment of the DMAA is made before final fixation with two compression screws. The adductors are carefully released from the lateral sesamoid and phalanx with a scalpel and the sesamoids realigned to lie inferior to the crista of the plantar surface of the first metatarsal head. If there is hallux valgus interphalangeus, then an Akin osteotomy of the proximal phalanx is also performed and fixed with a staple. The capsule is then double-breasted and the skin closed with subcuticular sutures. Patients mobilise with a heel weightbearing shoe for 6 weeks. Typical pre- and post-operative weight-bearing radiographs can be seen in Fig. 1a, b.

The mean age at the time of surgery was 14.1 years (range 10-17 years). Previous studies have included patients from the age of 9 through to 18 years with comparable mean ages [9-11]. These studies have not attempted to differentiate between those patients with an open physis or not, presumably because of the variable age at closure and the difficulty in making this distinction
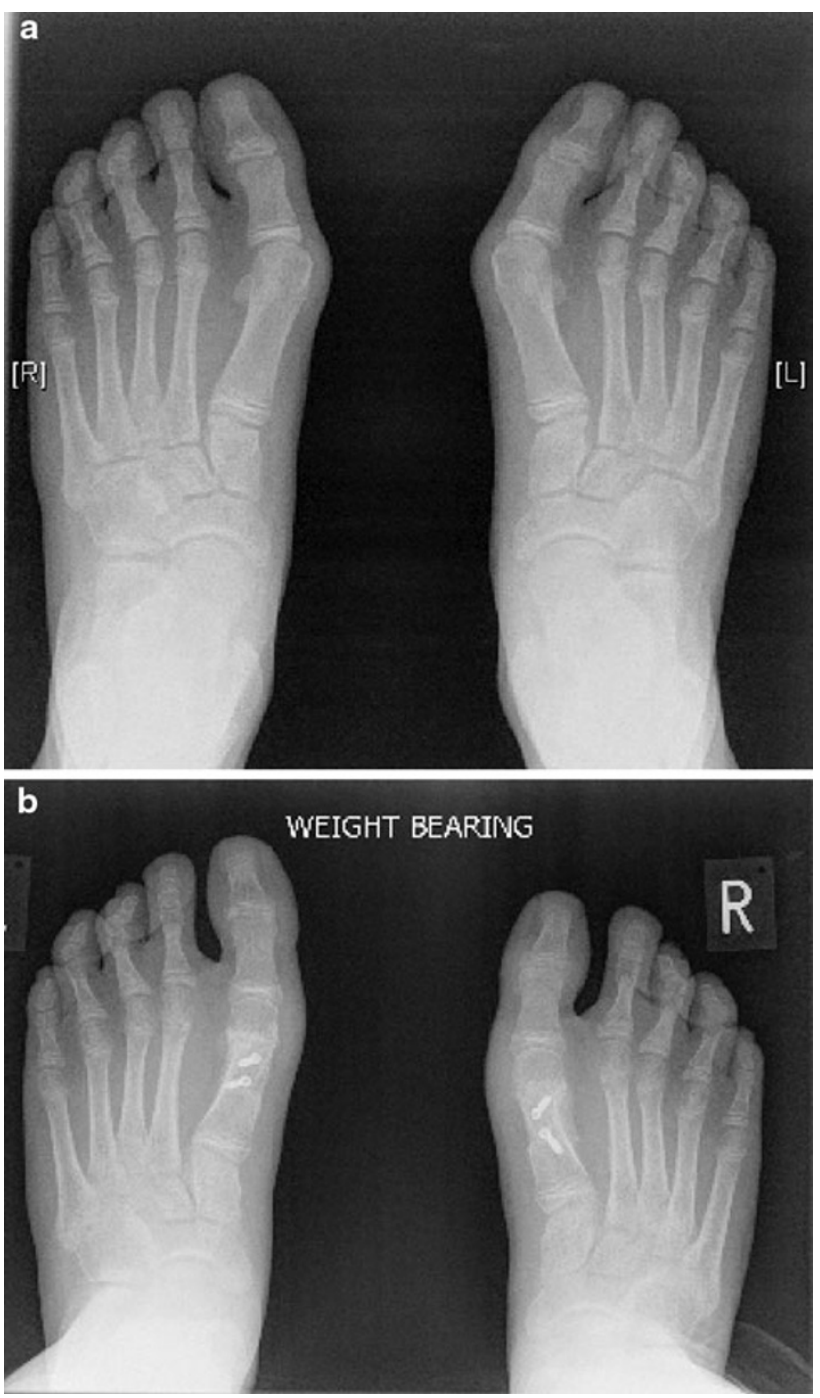

Fig. 1 a A typical pre-operative weight-bearing radiograph. b Postoperative radiograph of the same patient

radiographically when closure is occurring. To allow some differentiation between younger and older patients within the adolescent spectrum, we have a subgroup of patients aged 14 years or under and a subgroup of patients aged 15-17 years (at the time of surgery). In the younger subgroup, there were 15 patients ( 22 feet), of which 4 patients (5 feet) also underwent an Akin osteotomy. Of the older subgroup, there were 14 patients (22 feet), of which 6 patients (7 feet) also underwent an Akin osteotomy.

At final clinical follow up, the AOFAS Hallux Metatarsophalangeal-Interphalangeal Scale score was recorded, as well as the overall satisfaction [12]. The mean follow up was 38.6 months (range 6-60 months). The mean radiographic follow up was 14.7 months (6-60 months). This is shorter than the clinical follow up, as further radiographs could not be justified for patients for whom further intervention was not required. All radiographs were assessed by 
a single author and then repeated by a second author. Pearson's $r$ coefficient was calculated for the inter-metatarsal angle (IMA), HVA and DMAA both pre- and post-operatively to assess the inter-rater reliability. The Student's $t$-test was used to assess normally distributed data for differences between two variables. Statistical significance was taken as a $p$-value of less than 0.05 .

\section{Results}

At final follow up, the mean AOFAS score was 94.2 (54-100). Of all patients, $93 \%(26 / 28)$ were either satisfied or very satisfied. Of these patients, 16 were very satisfied, ten were satisfied and two recorded a poor result. Of the two patients who recorded a poor result, one female patient, aged 15 years at the time of the original surgery, has been listed for revision surgery after a significant symptomatic recurrence after 3 years. The other patient who recorded a poor result was a healthy girl, aged 17 years at the time of surgery, with a mild symptomatic recurrence who did not wish to have any further intervention. Additionally, there were five other mild recurrences on clinical examination, but without any symptoms or dissatisfaction. Mild recurrent deformity was that as defined by the alignment section of the AOFAS Hallux Metatarsophalangeal-Interphalangeal Scale [12]. Overall, when combining the two symptomatic recurrences with the five non-symptomatic recurrences, there was a recurrence rate of $18 \%$ (7/39 feet).

The mean pre-operative HVA, IMA and DMAA were $34.8^{\circ}, 15.9^{\circ}$ and $16.0^{\circ}$, respectively. At final follow up, the post-operative HVA, IMA and DMAA were $16.3^{\circ}, 8.8^{\circ}$ and $9.2^{\circ}$, respectively. All three measurements were statistically significant and the relevant confidence intervals and $p$-values can be seen in Table 1.

Table 2 illustrates the pre-operative radiographic results for the patients who have recorded either satisfactory or very satisfactory results at final follow up and for the patients with clinical recurrence. There were no significant differences between the two groups, although the mean IMA is higher in the group with recurrence and almost reaches significant levels.

Table 1 Mean hallux valgus angle (HVA), inter-metatarsal angle (IMA) and distal metatarsal articular angle (DMAA) values pre- and post-operatively for all patients

\begin{tabular}{lll}
\hline & Pre-operative & Post-operative \\
\hline HVA $\left(^{\circ}\right)$ & $34.8(95 \%$ CI 32.9-36.7) & $16.3(95 \%$ CI 14.0-18.6)* \\
IMA $\left(^{\circ}\right)$ & $15.9(95 \%$ CI 15.0-16.8) & $8.8(95 \%$ CI 8.0-9.6)* \\
DMAA $\left(^{\circ}\right)$ & $16.0(95 \%$ CI 14.5-17.5) & $9.2(95 \%$ CI 7.7-10.7)* \\
\hline
\end{tabular}

Significance assessed using the Student's $t$-test

$* p<0.001$
Table 2 Mean pre-operative HVA, IMA and DMAA values for satisfied/very satisfied patients versus patients with clinical recurrence

\begin{tabular}{lll}
\hline & $\begin{array}{l}\text { Satisfied/very } \\
\text { satisfied }\end{array}$ & Recurrence \\
\hline HVA $\left(^{\circ}\right)$ & $34.2(95 \%$ CI 32.0-36.4) & $\begin{array}{c}39.1, p=0.068(95 \% \mathrm{CI} \\
35.0-43.2)\end{array}$ \\
& & $17.5, p=0.054(95 \% \mathrm{CI}$ \\
IMA $\left(^{\circ}\right)$ & $15.5(95 \%$ CI 14.4-16.6) & $16.0-19.0)$ \\
& & $15.2, p=0.621(95 \% \mathrm{CI}$ \\
DMAA $\left(^{\circ}\right)$ & $16.1(95 \%$ CI 14.4-17.8) & $12.2-18.2)$
\end{tabular}

Significance assessed using the Student's $t$-test

Table 3 Pearson's $r$ coefficient values between two independent assessors

\begin{tabular}{lll}
\hline & Pre-operative & Post-operative \\
\hline HVA & 0.97 & 0.98 \\
IMA & 0.80 & 0.91 \\
DMAA & 0.57 & 0.88 \\
\hline
\end{tabular}

All the radiographs were independently reviewed by a surgeon from another clinical team. Pearson's $r$ coefficient values are shown in Table 3.

A summary of the overall results can be seen in Table 4 and compared to the other available case series. Subgroup data are demonstrated in Table 5 for patients aged 14 years or under and patients aged 15-17 years, along with data differentiating the patients who had undergone an additional Akin osteotomy from those who had not.

The osteotomies united both clinically and radiographically for all patients. There were no wound infections and no symptoms of transfer metatarsalgia.

\section{Discussion}

To our knowledge, there have been three case series in the peer-reviewed literature of adolescent patients with bunions being managed using the scarf osteotomy [9-11]. Table 4 summarises the clinical and radiographic outcomes of these three papers and compares them to this case series. Our mean AOFAS score of 94.2 indicates an overall good clinical outcome for our patients. It can be seen from Table 4 that it is not as high as that reported by Weil's group (Shine et al. [10]), but our data is from a much larger cohort of patients [10]. In our case series, one patient has been listed for revision surgery and this patient recorded an AOFAS score of only 54, whereas in Weil's group, one patient underwent revision surgery after recording a much higher AOFAS score of 93. This high score is incongruous with the clinical outcome and it is not clear what the level 
Table 4 A comparison of the clinical and radiographic results of the published case series

$* p<0.05$

Table 5 A comparison of the clinical and radiographic results of the published case series

\begin{tabular}{lllll}
\hline & $\begin{array}{l}\text { Salmeron et al. [11] } \\
(n=19)\end{array}$ & $\begin{array}{l}\text { George et al. [9] } \\
(n=19)\end{array}$ & $\begin{array}{l}\text { Shine et al. [10] } \\
(n=14)\end{array}$ & $\begin{array}{l}\text { Our series } \\
(n=39)\end{array}$ \\
\hline AOFAS & & 80 & 96 & 94.2 \\
$\begin{array}{l}\text { Satisfaction (very satisfied/ } \\
\text { satisfied) }\end{array}$ & $53 \%$ & $52 \%$ & & $93 \%$ \\
Symptomatic recurrence & $9 / 19$ & $7 / 19$ & $1 / 14$ & $2 / 39$ \\
Symptomless recurrence & - & - & - & $5 / 39$ \\
Pre-operative HVA $\left(^{\circ}\right)$ & 28 & 34 & 27.4 & 34.8 \\
Post-operative HVA $\left(^{\circ}\right)$ & 17 & 25 & $12.8^{*}$ & $16.3 *$ \\
Pre-operative IMA $\left(^{\circ}\right)$ & 15 & 14 & 14.3 & 16.9 \\
Post-operative IMA $\left(^{\circ}\right)$ & 9 & $8.5^{*}$ & $5.6^{*}$ & $8.8^{*}$ \\
Pre-operative DMAA $\left(^{\circ}\right)$ & 13 & 17.4 & 24.5 & 16 \\
Post-operative DMAA $\left(^{\circ}\right)$ & 11 & 15.6 & $8.8^{*}$ & $9.2^{*}$ \\
\hline
\end{tabular}

\begin{tabular}{lllll}
\hline & $\begin{array}{l}\text { Patients aged } \\
10-14 \text { years } \\
(n=22)\end{array}$ & $\begin{array}{l}\text { Patients aged } \\
15-17 \text { years } \\
(n=17)\end{array}$ & $\begin{array}{l}\text { Scarf osteotomy } \\
\text { alone }(n=27)\end{array}$ & $\begin{array}{l}\text { Scarf plus } \\
\text { Akin }(n=12)\end{array}$ \\
\hline AOFAS & $98.4(88-100)$ & $89(54-100)$ & $97.1(88-100)$ & $91.4(54-100)$ \\
$\begin{array}{l}\text { Satisfaction (very satisfied/ } \\
\text { satisfied) }\end{array}$ & $93 \%$ & $93 \%$ & $96.5 \%$ & $90 \%$ \\
Symptomatic recurrence & $1 / 22$ & $1 / 17$ & $1 / 27$ & $1 / 12$ \\
Symptomless recurrence & $2 / 22$ & $3 / 17$ & $4 / 27$ & $1 / 12$ \\
Pre-operative HVA $\left(^{\circ}\right)$ & 33.6 & 36.7 & 35.1 & 34.5 \\
Post-operative HVA $\left(^{\circ}\right)$ & $15.1^{*}$ & $17.7^{*}$ & $15.5^{*}$ & $16.2^{*}$ \\
Pre-operative IMA $\left(^{\circ}\right)$ & 15.9 & 16.3 & 15.8 & 15.9 \\
Post-operative IMA $\left(^{\circ}\right)$ & $8.2^{*}$ & $9.3^{*}$ & $8.9^{*}$ & $8.6^{*}$ \\
Pre-operative DMAA $\left(^{\circ}\right)$ & 16.3 & 16.4 & 16.3 & 16.6 \\
Post-operative DMAA $\left(^{\circ}\right)$ & $9.5^{*}$ & $8.8^{*}$ & $8.2^{*}$ & $9.6^{*}$ \\
\hline
\end{tabular}

$* p<0.05$

of recurrent deformity actually was. Weil's group did have the longest follow up of all the case series; however, it was partially skewed by 1 patient ( 2 feet) with a follow up of 18 years. Overall satisfaction was not recorded by Shine et al. [10].

The clinical results reported by George et al. [9] and Salmeron et al. [11] were not as favourable as those of Weil's group, with overall satisfaction rated as just over $50 \%$ in each group and rates of symptomatic recurrence of 7/19 and 9/19, respectively. In the case of Salmeron et al. [11], recurrences were occurring at an early stage with a mean follow up of 15 months. Salmeron et al. [11] concluded that those patients with a larger initial IMA and a normal DMAA did, however, have good results. We did not find this link and Table 2 illustrates that, in our case series, there was no statistically significant difference between the pre-operative radiographic measurements of the satisfied/very satisfied compared with the group with recurrence. Additionally, there were no differences in the demographic data between these two groups. George et al. [9] also did not find any significant differences in their data between those patients who had a good outcome and those with recurrence. On the basis of the data we have presented, we have not been able to predict which patients may have an excess risk of recurrence from radiographic parameters.

In terms of radiographic parameters, our results demonstrate good correction of HVA, IMA and DMAA, which can be seen in Table 1 and compared to the other published case series in Table 5. Our radiographic follow up is not as long as our clinical follow up data but does reflect the good outcomes achieved and is similar to that of the data of Salmeron et al. [11]. It is noteworthy that our group of patients has the most significant pre-operative deformity of all the case series in terms of the mean HVA and IMA. Shine et al.'s [10] case series has, by far, the largest preoperative mean DMAA of $24.5^{\circ}$. Our mean DMAA of $15.9^{\circ}$ is more comparable to the other two case series mentioned. The higher rates of satisfaction in our case series, compared to George et al. [9] and Salmeron et al. [11], could be linked to the increased level of pre-operative deformity; however, in our series, we could find no 
significant differences in the pre-operative deformity levels of those patients with a good outcome and those with recurrence (see Table 2).

Although the DMAA is known to be larger in cases of adolescent hallux valgus over that found in adults [13], we were surprised at the very large mean DMAA of $24.5^{\circ}$ found by Shine et al. [10]. On this basis, we elected to scrutinise the accuracy of our values independently, with measurement by a surgeon from another clinical team and the calculation of Pearson's $r$ coefficient for pre- and postoperative HVA, IMA and DMAA (see Table 3). The values found indicate good inter-rater reliability, particularly for the HVA and DMAA. Pearson's $r$ coefficient for preoperative DMAA was 0.57 , reflecting the slightly more subjective nature of this measurement. Despite this, our mean pre-operative DMAA of $15.9^{\circ}$ is similar to that found by Salmeron et al. [11] and George et al. [9].

The results of the scarf osteotomy for the treatment of hallux valgus in the adult population are excellent, with high patient satisfaction, good AOFAS scores post-operatively and low recurrence rates $[14,15]$. On this basis, it might seem sensible to advise patients and their parents to delay surgery until they reach skeletal maturity, because of the improved outcomes seen in adult populations. Typically though, the mean age of patients in adult studies falls somewhere in the 5th or 6th decades of life and, so, it is not yet clear that patients with significant juvenile hallux valgus will do better if they delay any surgical intervention. Further studies are needed in order to assess the outcomes of patients who have developed symptomatic hallux valgus deformity as an adolescent but who have delayed their surgery until reaching their $3 \mathrm{rd}$ decade of life. It may be that their outcomes are different to those undergoing surgery in their 5th and 6th decades of life.

We have found that the scarf osteotomy appears to produce better results than distal and double osteotomies, for which the outcomes have not been reliable [6-8]. Our outcomes have approached the success of Shine et al. [10] and appear to have exceeded those of the other studies. It is not entirely clear as to why there are such differences in the outcomes between different series. We believe that careful counselling of patients and their parents is important in managing their expectations effectively. In our series, all cases have been either performed or directly supervised by a single surgeon whose practice largely involves paediatric orthopaedic surgery and foot and ankle surgery. Therefore, in cases of adolescent hallux valgus, it may be sensible to refer to a subspecialist with the relevant experience in treating these cases. Should there be a recurrence, we feel that the scarf osteotomy still allows revision options after skeletal maturity has been reached. The option of performing a basal osteotomy remains and an Akin osteotomy can be added, if it has not already been undertaken.
Patients with juvenile hallux valgus do present a difficult management problem, as they can have significant symptoms and it is known that non-operative measures do not halt the progression of the deformity [5]. Our case series is the largest presented to date in the adolescent population and demonstrates that a good clinical outcome can be achieved for the majority of patients, with 26 out of 28 patients being either satisfied or very satisfied with their final outcome. On this basis, we feel that scarf osteotomy is a reasonable treatment option in cases of significant deformity, combined with troublesome symptoms and failed non-operative management. In our group of patients, there was a $5 \%(2 / 39)$ rate of symptomatic recurrence and a further $13 \%(5 / 39)$ with some evidence of mild clinical recurrence without symptoms. Despite an overall good result, patients and their parents need to be made aware that the rate of recurrence is higher than that found in the adult population.

\section{References}

1. Meyer M (1926) Eine neue modifikation der hallux-valgusoperation. Zbl Chir 53:3265-3268

2. Barouk LS (2000) Scarf osteotomy for hallux valgus correction. Local anatomy, surgical technique, and combination with other forefoot procedures. Foot Ankle Clin 5(3):525-558

3. Weil LS, Borelli AN (1991) Modified scarf bunionectomy: our experience in more than 1000 cases. J Foot Surg 30:609-622

4. Hewett CA (1978) Anglo-Saxon carpentry. Anglo-Saxon England 7:205-229. doi:10.1017/S0263675100002945

5. Kilmartin TE, Barrington RL, Wallace WA (1994) A controlled prospective trial of a foot orthosis for juvenile hallux valgus. J Bone Joint Surg Br 76:210-214

6. Scranton PE Jr, Zuckerman JD (1984) Bunion surgery in adolescents: results of surgical treatment. J Pediatr Orthop 4:39-43

7. Das De S (1984) Distal metatarsal osteotomy for adolescent hallux valgus. J Pediatr Orthop 4:32-38

8. Johnson AE, Georgopoulos G, Erickson MA, Eilert R (2004) Treatment of adolescent hallux valgus with the first metatarsal double osteotomy: the Denver experience. J Pediatr Orthop 24:358-362

9. George HL, Casaletto J, Unnikrishnan PN, Shivratri D, James LA, Bass A, Bruce CE (2009) Outcome of the scarf osteotomy in adolescent hallux valgus. J Child Orthop 3:185-190

10. Shine J, Weil L Jr, Weil LS Sr, Chase K (2010) Scarf osteotomy for the correction of adolescent hallux valgus. Foot Ankle Spec $3: 10-14$

11. Salmeron F, Sales de Gauzy J, Galy C, Darodes P, Cahuzac J-P (2001) Traitement de l'hallux valgus de l'enfant et de l'adolescent par ostéotomie scarf. Rev Chir Orthop 87:706-711

12. Kitaoka HB, Alexander IJ, Adelaar RS, Nunley JA, Myerson MS, Sanders M (1994) Clinical rating systems for the ankle-hindfoot, midfoot, hallux, and lesser toes. Foot Ankle Int 15:349-353

13. Robinson AHN, Limbers JP (2005) Modern concepts in the treatment of hallux valgus. J Bone Joint Surg Br 87:1038-1045

14. Kristen KH, Berger C, Stelzig S, Thalhammer E, Posch M, Engel A (2002) The SCARF osteotomy for the correction of hallux valgus deformities. Foot Ankle Int 23:221-229

15. Jones S, Al Hussainy HA, Ali F, Betts RP, Flowers MJ (2004) Scarf osteotomy for hallux valgus. A prospective clinical and pedobarographic study. J Bone Joint Surg Br 86:830-836 